\title{
Projects in networked learning: European experiences
}

Reports from panel sessions

\section{INTRODUCTION}

In the last 5 years 'networked education' has come to refer not only to computer networks in education but to co-operative networks of educators working together to research, address issues and define good practice in the use of ICTs in education. At the ComNEd99 conference, European colleagues from a number of these co-operative projects presented panel sessions where they shared their work, the issues and findings arising out of their work. Each of these panel sessions was attended by rapporteurs who have written the following accounts of the sessions and projects. Where possible World Wide Web addresses have been provided to allow the reader to seek out more information about each of the projects. The paper ends with a number of reports of Finnish projects. These projects highlight good practice in networked education taking place in Finland, the host country of ComNEd99.

\section{TRAINING EDUCATORS THROUGH NETWORKS AND DISTRIBUTED SYSTEMS (TRENDS)}

Chair: Raymond Morel, $\mathrm{CH}$

Presenter: Chryssa Koutra, GR

Rapporteur: Jan Wibe, NO

Detailed information about the project at: www.Irf.gr/english/trends/ trendshome.html

TRENDS started in 1996 and ended in September, 1998. The following countries were involved: France, Greece, Italy, Portugal, Spain and United Kingdom. The Lambrakis Research Foundation in Greece was the project leader. In each country the main partners involved were ICT training 
centres, schools with school-leaders, and national telecommunications companies.

The project had the following objectives:

- Training in the use of ICT in teaching and learning;

- Development of a school-based (on-the-job), open-distance learning (ODL)/ICT-based training model for in-service teachers;

- Development of a teacher training network;

- Validation/Evaluation in the national and European environment.

The following points were the main focus of the presentation and discussion.

\section{$2.1 \quad$ Training centres}

The training centres played a crucial role in the project. In addition to training, they were also suppliers of educational resources. It was said that the centres had no or very little contact with schools before the project and that the project established such contacts. In the beginning they could not offer all of the services needed, but this improved through the project period. In many training centres, they have now established so-called 'Virtual Training Centres' with a broad scope of services for teachers.

\section{$2.2 \quad$ Selection of schools}

The only criteria for selecting schools to take part was that they should be equipped with computers. This lead to some difficulties in the project because there were significant differences in the various schools' experience and expertise and also in what they wanted to do in collaboration with other schools. It is perhaps unfair to look back to 1996 from the perspective of 1999 , but the outcome of the project could have been better if there had been other criteria for taking part in the project. For example, choosing teachers with common interests and more experience with ICT may have proved beneficial. Particular subject areas could also have been selected for international co-operation.

\subsection{The schools}

The role of the school leaders was an important feature of the project. While not experts, generally they were familiar with ICT, and were close to the daily life of the schools. They acted as an interface between the schools and the training centres and acted as both facilitators and brokers. Generally, the project seemed to be a success within the schools, due in part to the effective role of these leaders. At times, overload for school leaders caused tension in the schools. 


\subsection{National and international activity}

An important aim of the project was to create an European network of teachers. At the start of the project, international co-operation was at the forefront. But over time the various elements of the projects became more focused at the national level and finally, in some projects, at the international level. There were many reasons for this, some of which were cultural differences. Generally, the teachers were well supported within their own schools but lacked the motivation to go beyond their school. Self learning by the teachers was seen as more valid than collaborative learning. The teachers did not see the wider national or international network as a space for collaboration.

The international aspect of the project was clearly the weakest part of it. Common elements were not stressed enough. International discussions did not appeal to the teachers and there was not enough stimulus from the moderators. This may have been different if, at the beginning of the project, there had been clear criteria for participation; carefully selected schools based on such criteria as school profiles and leaders' profiles; and clearly defined aims that all participants were expected to work towards.

\subsection{Accreditation}

The teachers taking part in the project wanted official recognition and accreditation for the work they did and the expertise they built up during the project. For example, a certificate recognising the learner activities would have been appropriate. The teachers also saw the project as part of their personal career development. The school leader's role was crucial within the project yet they were also not rewarded through official recognition and accreditation. This created tension in the schools. The project administration now recognise the importance of this aspect for future projects. There must be clear motivation and recognition for teachers who take part in such projects. 
3. FORMATION DES ENSEIGNANTS AUX TECHNOLOGIES
DE L'INFORMATION ET DE LA COMMUNICATION:
CHANGEMENTS ET EVOLUTIONS (FETICHE)

Chair: Bernard Cornu, FR

Presenters: Patricia Marzin, FR, Mario Maia and Cecilia Monteiro, PT, Deryn Watson and Barry Blakely, UK, Raymond Morel, CH, Bernard Cornu, FR, Leena Vainio and Tuija Karppanen, FI

Rapporteur: Don Passey, UK

Detailed information about the project at:www.grenoble.iufm.fr/tic/ fetiche.htm, French language only

The project FETICHE was an open-distance learning (ODL) European project run as part of the SOCRATES Programme in 1995-97. The project involved 6 partner institutions from 5 European countries: Institut Universitaire de Formation des Maitres (IUFM) of Grenoble, France; University of Helsinki, Finland; King's College, London, United Kingdom; Escola Superior de Educacao de Lisboa, Portugal; CNRS-CEGELY, Lyon, France; CIP and TECFA, Geneva, Switzerland.

The stated objectives of the project were to predict the nature of a future teaching profession when teachers use information and communication technologies (ICT). It aimed to identify pedagogic competencies required, and to develop teacher and teacher trainer competencies through the use of ODL, as well as to facilitate co-operation between teacher training institutions in Europe, and to be reflective of those training practices undertaken. The outcomes of the project included state-of-the-art integration of aspects of ICT use into teacher training education in the partner institutions, reports about the experiments carried out in each partner country, and the production of two written documents that offered recommendations for users and policy makers.

The session offered an overview of the project and its outcomes, as well as more specific details of the experiments carried out in four of the partner groups. The session overview indicated that the major project results had been used to inform the production of two overview documents. The 'Users' Needs' document indicated that teacher training education in the future should be underpinned by having the use, role and concepts of ICT integrated into the curricula of schools and teacher training institutions. It indicated that teacher education should have full access, full infrastructure and availability to global networking as essential elements for all schools.

The project showed that there is a merging of pre-service and in-service teacher education into a single lifelong professional development process, and that all schools and teacher education institutions should have a pro- 
active policy to address this aspect. The 'Guidelines for European Education Decision Makers' indicates that outcomes show that a necessary starting point for developing appropriate future needs for teacher training should be from a position of having a policy in place, which should tackle the needs of developing practice where conceptual shifts involve the taking of steps to a 'new' cultural position. The project showed the need for developing integrated tasks and activities to exemplify curriculum practice, but that each teacher or student teacher will need to experience open learning methods for themselves. The project recommends that networks are used to bring classrooms and institutions together, and that certain levels of equipment and human resources will be necessary to enable particular levels of progress in these forms of ongoing development.

\subsection{Escola Superior de Educacao de Lisboa, Portugal}

Two experiments were undertaken by this partner institution. The first experiment involved only pre-service teacher education, and was concerned with developing pedagogical practice. The outcomes of this experiment showed that Internet use can result in benefits and gains in pedagogic terms, but that it is necessary to engage teachers and teacher trainers at a subject level to consider more carefully the potential uses of the Internet in teaching and learning. The second experiment involved the continuum from the preservice to the in-service sectors, and was concerned with the training of teacher trainers. This experiment involved the design and development of a training programme for teacher trainers and teachers in schools. The training programme considered pedagogical practice in schools, and involved seminars with teacher trainers, school teachers, and student teachers in schools, as well as discussion forums. The outcomes of this project indicated the need for teachers to have more time to integrate use into their practice, and the need to be alerted to the advantages of using the practice in daily work. The project had ultimate impact at an institutional level.

\subsection{King's College London, United Kingdom}

The experiment in this partner institution involved the introduction and use of the World Wide Web (WWW) as a common interface for a forum to enable discussion and communication between researchers, teacher trainers and teachers in a PGCE course. The experiment involved three subject areas (modern foreign languages, religious education, and science), with three university teacher trainers and six school teacher co-tutors. A number of problems were highlighted at the time of the project, including the fact that the ICT equipment present in each of the schools was different and different to that within the teacher training institution, that the schools had limited 
communications equipment and access to such equipment, and that setting up the systems took a great deal longer than expected. The access provided ultimately was Web-based, and schools were given modems and remote access accounts on the teacher training institution's email system. Support was provided for those involved, and was reported as becoming a significant part of the experiment. Teacher trainers were given one-to-one training, while school teachers were offered support through visits from research staff and a specifically designed help sheet.

The Web-based discussion areas covered six topics. However, contribution levels were much lower than anticipated, the majority of discussion being in the 'Meeting Point' area, with conversations being generally linear, and mostly about non-professional matters. Issues identified by the experiment were that access for teachers and teacher trainers must be simple, that the technology used must be able to support access and reaction adequately, that the imposition of structure on the access might not be helpful, that joint interest must be aroused before use is stimulated, that wide access through the World Wide Web was considered by participants to be useful, and that the archiving facility of the Forum aided the research activity.

Fundamental outcomes identified were that technology and infrastructure are not necessarily critical to outcomes, and that having a physical ICT presence does not in itself ensure communication results. However, the average technical infrastructure in schools at that time did not encourage use. To support use, the experiment outcomes suggested that developing levels of conversation or discussion requires an appropriate stimulus, that there needs to be a level of commonality across users, and that users need to have concern for the pedagogy of the subject rather than the pedagogy of teacher education itself.

\subsection{Institut Universitaire de Formation des Maîtres (IUFM) of Grenoble, France}

The experiment in this partner institution involved the development of co-operative work for student teachers, tutors and trainers through the use of video-conferencing and email. A system was developed to train student teachers to work collaboratively through class to class communication, to offer distance class observations for teacher trainers, and virtual visits to classrooms. Eleven primary schools were equipped with ICT systems, as was the IUFM at Grenoble. In all, twelve teacher trainers, twenty-three primary school student teachers and their tutors in schools were involved. Daily video-sessions were used to develop collaborative practices, as well as 
the use of chat meetings, and teacher observation of student teachers through video-conferencing techniques in geography and art lessons.

The main outcomes of the project were the realisation that different ways of working with student teachers, and different pedagogical styles had developed and were recognised by those involved. The techniques used enhanced critical practice and reflection by enabling regular contact and comment. It was found that some student teachers experienced difficulties in school integrating ICT into practice, however, and while the tools available were used for communicating externally from school, there was no evidence that internal communication could be provided through this medium. The experiment showed that training was a requirement for those in the future, and the IUFM developed a considered plan as a consequence.

\subsection{University of Helsinki, Finland}

The experiment in this partner institution was integrated with the fiveyear national plan produced in 1995 by the Ministry of Education, which involved the linking of schools and educational establishments to an information network. This plan considered also the development of initial teacher training education, and the organisation of continuing education. The experiment involved the development and use of a teacher training course that would be run over 5 study weeks, involving initially 1 or 2 teachers from each participating school. The course focused on pedagogic concerns, the development and integration of ICT in subjects and on schoolwide developments as a whole, with teachers developing plans and implementing them by involving other teachers. The course was delivered through two face-to-face sessions of two days duration, and one session of a single day's duration. Sessions run at a distance were also involved, as well as email contact, a discussion list, World Wide Web pages, videoconferencing and audio-lectures, project work and tutoring at an individual level.

Aims of the research for the experiment were identified and stated in advance. Of 234 teachers who were initially approached, 91 responses were received (considered to be a representative group across schools as a whole), but all schools were located in the area around Helsinki and the southern district of Finland. Features and background factors of respondents were considered in terms of whether they related to particular levels or types of ICT use. It was found that most respondents were female (65\%), that most (about $80 \%$ ) of the respondents were between 25 and 45 years of age, that some $90 \%$ had a university degree, and that many (some $41 \%$ ) were subject teachers. When teacher skills, attitudes and views were identified, these indicated that there was a need to consider how to motivate other teachers, 
how to implement appropriate use of tools, how to tutor distance learning, and to share 'new' ideas. The experiment had effects at a national level: the outcomes indicated that training should perhaps involve 2 to 4 members of a school rather than one or two, that teachers should be made aware of how to develop possible ICT strategies in school and be offered examples of 'good' practice.

\subsection{Discussion points}

Each project was uniquely different, and the ways in which outcomes were utilised were specific to their contexts, and to the context of the stage reached by respective national developments at that time. The four presentations generated a range of issues, and a range of comments arose from those present in the audience. Results suggested that when developing innovative teacher uses, attendance of two or more participants from a school is necessary, and that conceptions of technology use should be developed fully within any teacher training activity. Strong mentoring systems may be needed to support teacher development, but teachers may listen to other teachers more than they do to others. Those willing to undertake innovative practice are not necessarily age related, but are more likely to be related to risk-taking willingness. Stages of learning, levels of uncertainty, risk-taking willingness, boredom levels, assessment needs, and perceived time availability are all factors that influence innovative practice and outcomes. Women teachers may take longer to engage in innovation, but then can become highly enthusiastic users. Pre-service teachers are often asked to learn a large number of things in a limited period of time.

Clearly the outcomes of this project relate to results from those of other innovative projects, and these results help to confirm elements of the wider picture of our understanding of the innovative constructive demands for developing innovative practice and implementation effectively.

\section{4._LINGU@NET-EUROPA}

Chair: Raymond Morel, $\mathrm{CH}$

Presenters: Clare Power, UK, Pierre Dunand, CH, Aino Korhonen, FI

Reporter: Gail Marshall, US

Detailed information about the project at: www.linganet.org.uk.

Lingu@net-Europa is a multilingual virtual resource centre designed to support the teaching of foreign languages. The three papers in this panel session addressed the history, goals, content, programme structure and features as well as issues related to management and evaluation of the Lingu@net-Europa materials, resources, and interface. 


\subsection{History and goals of the project}

The first third of the panel presentation addressed Lingu@net-Europa's history, goals and content. The website, funded by the European Commission (DGXXII), Lingu@net-Europa provided information links to quality-assured online resources in Dutch, English, French and German to eleven European countries and Canada during the first pilot year. In the next two years it is planned that Italian and Spanish language materials and resources and then Eastern European-based materials and resources will be added to the metadata core.

The project's goal is to support the mobility of citizens and business, enhance lifelong learning, motivate teachers, trainers and researchers, and promote the sharing of expertise, experience and resources. Lingu@netEuropa has been designed as a one-stop shop with many different source and target languages. It can be accessed from any computer with an Internet connection and enhances collaboration across borders and linguistic communities. The quality assurance process, designed to ensure that materials and resources contained in the metadata core are of high standard, was explained as well as the procedures used in the construction and modifications of the entire website. The core programme's management procedures, featuring dynamic processing of records, were illustrated.

\subsection{Content anà processes of Lingu@net-Europa}

The second part of the presentation featured a demonstration of access to the materials, professional development resources and research reports. Sample records of foreign language materials were accessed via the World Wide Web and procedures for selecting both source and target materials were also demonstrated.

\subsection{Evaluation of the materials and procedures}

The third part of the presentation described evaluation strategies at four levels: data from workshops designed to present Lingu@net-Europa, data from focused user groups who completed online questionnaires, data from larger groups invited to provide evaluative comments and data from the large group of users who have accessed the materials and resources since the inception of the project. Both quantitative and qualitative data have been collected and a variety of data summaries, all showing a high level of user satisfaction, were displayed and analysed.

Members of the audience commented that the project's resources are needed by the educational community and they also asked if the project assisted educators in establishing partnerships with classrooms and 
individual students around the world. Project personnel reiterated the fact that the principal goal of the project was to provide web-based materials and resources for education and professional development and was not designed to serve as a clearinghouse for partnerships designed to facilitate person-toperson or classroom-to-classroom communication exchanges.

The fact that Lingu@net-Europa provides resources and materials at no cost to users was viewed as a valuable aspect of the project, and plans to eventually expand both the number of source and target language materials and the access to those materials to a wider geographical range was viewed favourably by the audience.

\section{THE TELEMATICS FOR TEACHER TRAINING PROJECT (T3)}

Chair: Ian Lam, NL

Presenters: Niki. Davis, UK, Jyrki Pulkkinen FI, Donatella Persico, IT, Andrée Klein, FR, Ditte Lockhorst, NL

Rapporteur: Hubert Christiaen, BE

Detailed information about the project at: http://telematics.ex.ac.uk/T3/

\subsection{The T3 project and questions it raised}

The Telematics for Teacher Training project was a project where seven European partners worked together to develop online courses in the areas of mathematics, languages, science and technology. Also courses for teacher trainers, for primary teachers and librarians were developed. It was a project in the framework of the Telematics Application programme of the European Commission. The project started in 1996, when online courses on the World Wide Web were still rare. Nevertheless it was decided from the beginning to use the Web. Although the project finished at the end of 1998, the results are still available at the above website.

While the project was quite successful, Niki Davis from the University of Exeter, the first presenter via a video-conference link, warned against too rosy picture being painted. Projects such as these need a lot of collaboration and very explicit guidelines about how partners are to collaborate. The project developed new insights on aspects of pedagogy, networking and collaboration and management of change. At the end of the presentation the question was asked what had been the most difficult thing to do. Niki Davis answered creating a common meaning for terms. Niki Davis also argued that experts should also use the technology in a way which fits with the beliefs and the traditional way of acting of teachers. 
The second presenter was Andrée Klein from the Institut Universitaire de Formation des Maîtres (IUFM), Grenoble, France. Her topic was New Roles of Learners and Teachers. From her experiences in the project she formulated some risks and needs of the autonomous learner. The main risks were isolation and 'the long distance runner syndrome'. To avoid this one should take care of:

- permanent technical support;

- pedagogical support: careful planning, reflection on collaborative knowledge;

- communicative support: the learners should describe to others what they do, confront their ideas with others and reconstruct their understanding about what they are studying.

Andrée left the audience with the following question: Should or could computers and conferencing software replace the social context of learning?

The third presenter was Donatella Persico from the Istituto Tecnologie Didaticche at Genoa, Italy, speaking on Social Structures for Virtual Learning Communities. From her experiences in running distance education courses she saw different structures arise between the participants and the tutors.

The first is the dissemination model. It is the closest to the face-to-face situation and characterised by a few students trained by tutors who are also the domain experts. The dominant communication is between the tutors and the trainees. The website is mainly an external resource of training material.

The second model is the peer-tutoring model. In this model tutors are not the experts in the domain. The website here had a more important role containing all the information on the course (goals, agenda, resources) Students work individually or in small groups following the activities of another student or group. This accounts for a domination of peer to peer communication. It allows a small group of tutors and experts to handle a relatively large group of trainees.

The third model is the two-level model. Here students are grouped locally, one of them acting as the local tutor. The participants are required to develop a project and have discussions with the other participants on methodological aspects. The website contains both learning material and dynamic course information. Remote tutors check and monitor the progress of the groups, providing them with learning material and encouraging discussions between the groups. Experts on the technical matters of the $\mathrm{CMC}$ environment assist in technical problems. Experts in the content domain could be consulted through the CMC system.

In this configuration communication took place both locally within each group and between groups at a distance. The existence of local groups allowed for the translation of course instructions and some material in the 
local language and to the adaptation of some guidelines to the local style of the students, which was felt of great importance for the success of some groups. This two-level model facilitated the communication between groups because the other groups and the remote tutors saw the groups as a single entity. It allowed for handling a high remote tutor/student ratio.

The question Donatella Persico asked at the end of her presentation was: what kind of virtual communities have you experienced and what comments do you have towards the advantages and drawbacks of different social structures?

The fourth presenter was Jyrki Pulkkinen, research manager at the University of Oulu, Finland. He spoke about the cultural context of webbased learning. In developing learning environments, mostly attention is given to learning theories and technology. The latter is usually considered as a neutral element although it influences the learning process and should rather be considered as an active component. The choice of technology to be used (e.g. chat versus email) will influence the learning process.

A third component, which should be considered, is the cultural dimension. Considering this component is really important for the adaptation of the learning situation to real life. In an international context there are many differences between participants, everybody bringing something of their own culture. In these circumstances, half a year is relatively short for forming a real learning community. There is a need for a common language, not only at the linguistic level but also at the semantic level. A better mastering of the common language (mostly English) may favour some participants and make them dominant in the exchanges. At the semantic level there is a need for having all participants giving the same meaning to terms.

The last presenter was Ditte Lockhorst from the IVLOS/Institute for Education, Utrecht University, the Netherlands. She put the four previous presentations in the perspective of one of the main evaluation research questions of the project: is there a European market for online teacher training? At the beginning of the project it was thought that this should be possible, but at the end there was much doubt about this. There are tremendous differences between the different countries. The are differences in national curricula, cultural differences, differences in pedagogical approaches, and technological thresholds. The international dimension of teacher training is still underdeveloped and in most places the initial teacher training is state owned. A commercial teacher training service would have to compete with subsidised organisations. 


\subsection{Issues from the discussion}

The following issues were raised during the discussion: virtual communities and differing social structures; feedback from the trainees; computers and conferencing software and the social context of learning; and appropriate technologies for different cultures. Each is discussed in turn below.

Different nationalities react quite differently to a situation. When looking at a video of classroom activities, some participants found everything normal but people from other countries were horrified. Students from certain countries are accustomed to a non-directive style and start working immediately, while others started a discussion and needed some more detailed instructions to start working. The second run of some courses worked better after trainers had added extra instructions to address these differences.

Jyrki Pulkkinen mentioned a lot of technical problems, but most participants remained motivated and liked the way they could work autonomously and individually. In the beginning of one project a high dropout was noticed, but the participants who continued were very enthusiastic. But do we know how many drop out in the traditional setting? Evaluation of the courses was based on web-based questionnaires, interviews and the products delivered by the participants.

The impression was that the environments are not completely satisfactory and that new techniques or software is needed. There is a need in the group to feel like a community by the exchanges they have. The question was asked why we talk of 'web-based learning' but not of 'bookbased learning'. A better term should be 'collaborative learning'.

There are different feelings about computers in different cultural contexts. For example, in developing countries teachers don't like a heavy use of computers. On the other hand most academics have rather a culture of writing and don't like video-conferencing.

Finally the remark was made that a lot of different technologies have been used in education, but that only the technologies which have had a commercial underpinning have survived. Education can not maintain technologies with constant subsidising unless they are technologies already in existence and use in other sectors in society. 


\section{EE-NET}

Chair: Raymond Morel, $\mathrm{CH}$

Presenters: Helmut Stemmer, AT, Vittorio Midoro, IT, Ella Kiesi, FI

Rapporteur: Pieter Hogenbirk, NL

Detailed information about the project at: www.ecmc.de/eenet/nav.html

EE-net stands for European Experts' Network for Educational Technology. It consists of individual members of 13 European countries. Its mission is to spread knowledge about multimedia and ICT use in education in order to promote individual growth and European co-operation, and develop competitiveness. EE-net produces a series of reports that aim to:

- highlight main issues of ICT policy and its implementation;

- disseminate effective implementation strategies and show barriers to progress;

- provide a critical overview of the challenges and implications confronting the development of ICT in education within Europe;

- where there is evidence, show the effects of introducing new digital technologies into education on learning and its organisation.

The first report of EE-net covers ICT in education policy. It is an analysis of policies and actions designed to implement new technologies in education systems, mainly at school level, in countries across Europe. The report is available on the web: http://www.becta.org.uk/Eenet. In the panel session the 9 recommendations in this report were presented and discussed.

\subsection{A holistic approach to policy development}

"A holistic model for policy development for ICT in schools, should be considered by policy makers. Future innovation needs to involve all players in the education system, including the public and private sector." It was clarified that this recommendation involves producers of hardware, software, teacher trainers, curriculum developers, schools, teachers, local communities and the government. Also the relationship between all these sectors should be addressed. If you start, as many countries do, only with the supply of hardware, it does not work. Also the holistic approach should apply to schools. It was recognised however that every sector has its own responsibility, so the governments should aim at commitment from the different sectors, rather than prescribing things to one of them, for example, the schools. 


\subsection{A bottom-up / top-down convergence}

"For teachers to take ownership and implementation ICT strategies effectively, policy makers should listen and respond to successful and appropriate ICT developments which start at the school level, when developing large-scale policies." It was agreed that the school level is very important. In examples of successful practices you should very carefully analyse which underlying conditions were favourable for this success. That could help to define the elements of the top-down measures, leaving the core of the process with the schools. There was a support for the idea not to develop in depth with model schools, but directly going for a broad approach. One other idea is to give grants for those schools which want to implement ICT, in exchange for sharing their ideas with others.

\subsection{Sustainability}

"Policies and strategies for implementation should be designed to achieve the sustainable and generalisable use of ICT in education. It should be borne in mind that sustainability can only be achieved through a synthesis of economic and human measures." Governments and local authorities should provide initial money for ICT in schools. But even more importantly, they should provide structural funds for maintenance and replacement. In that way ICT can be considered as a normal financial element of the school budgets.

\subsection{The curriculum}

"Ideally, comprehensive plans for implementing ICTs should start with learning targets related to the curriculum. Linked to this, examination and assessment systems should be reviewed to ensure that they are appropriate to the digital age." To integrate ICT into the learning targets would be a start, but at the same time it is important to improve the quality of education, didactics and pedagogy itself by ICT. In order to force teachers to really cover the ICT learning targets, the examination system should indeed be changed.

\subsection{Teacher training}

"Specific measures need to be taken to ensure that ICT use is covered in all pre-service training courses and that all serving teachers have access to appropriate in-service training that responds to their individual needs." Especially for the in-service training this is a real bottle-neck, because teachers are often themselves responsible for their training. Schools and government can only influence these matters by giving credits or incentives. 
Also it was mentioned that in-service and pre-service training should be have much the same goals and training aspects.

\subsection{A wider concept of learning}

"Policies and implementation actions need to recognise the wider concept of learning that generalised ICT use will bring and should reflect the consequential empowerment of the learner that is likely to take place. This empowerment will demand new and more subtle skills from teachers as they are less able to rely upon the formal didactic aspects of their role." Some people were favouring the wider concept of learning as the key element of teacher training. This has to do with the 'new' role of the teacher, however there was a preference to speak about an 'extended', or better, 'redefined' role. There was an agreement to link this recommendation strongly to the previous recommendation.

\subsection{The importance of research}

"Decision makers at all levels must take more account of existing educational research, within Europe and beyond, when formulating their educational policies and actions. Research on new topics with relevance for this area should also be initiated. Consideration should also be given to the literature on innovation and change at organisational level." This was agreed upon, with the suggestion to combine ICT research with other educational research.

\subsection{Content and national languages}

"Most countries need to address the issue of the shortage of Multimedia and Web-based content for educational use in national languages. It may in some cases require government pump-priming to stimulate market activity and it is sensible to encourage commercial developers to use teachers and others as advisors or to help at the trialling stage." It was mentioned that financing the development of software by the government often leads to experimental products, which are not commonly used. Two suggestions were given: solve the problem of copyright on materials which could be used in educational settings and stimulate software developers to invest in translation of foreign software.

\subsection{Evaluation}

"Central ministries and regional authorities should co-operate in gathering, analysing and disseminating data, not only on inputs into the system such as pupil/computer ratios, but also on process variables such as 
development and pupil/teacher access times and actual outcomes." There was a full agreement on this recommendation. EE-net wants to continue the job (which was supported by the audience). There will be more emphasis on certain themes. Furthermore EE-net wants to design and fill a database with the aspects and figures of all the nations involved.

\section{THE NORDIC EXPERIENCE}

Chair: Mike Aston, UK

Presenters: Peter Bollerslev, DK, Matti Sinko FI, Anna Kristiandottir, IS, Sindre Røsvik, NO, Kersti Hjertquist, SE, Ulf Vastrom, DK, Rapporteur: Erling Schmidt, DK

The chair, Mike Aston, opened the session by noting that the Nordic countries have an unique tradition for working together and co-operating on matters of culture and education. One of the areas for such collaboration is ICT in schools where a special unit has been formed under Nordic Council of Ministers. The Nordic Countries also have an especially good background for sharing ideas and inspiration on ICT in schools as the education systems in the different countries share common structures and traditions.

\subsection{Denmark (Peter Bollerslev)}

ICT is now integrated cross curriculum and on all levels in schools. The latest action plan for ICT in schools is a 'rolling plan' covering year 1998 2003 to be revised in 2000 . The plan deals with five central areas - each with its own goals and actions:

- Students and ICT;

- Teachers and ICT;

- Subject and ICT;

- Equal and flexible access to lifelong education;

- Co-ordination of ICT-based research and education.

Peter Bollerslev also drew attention to the fact, that what goes on in schools reflects the general development in society, and he presented some intriguing statistical background for this:

- $3 \%$ of IT investment in Denmark is connected with education;

- $52 \%$ of homes have a PC;

- $31 \%$ have access to the Internet;

- the use of PC's and Internet in homes rises with level of education. 


\subsection{Finland (Matti Sinko)}

All the Nordic countries are relatively small and have thereby been forced to co-operate. But at the same time there has been a brotherly competition which also has stimulated development. Nordic countries have been able to share and learn from one another. The use of ICT itself has also structured co-operation moving from traditional conferences to sharing experiences continuously through networking. The collaboration has especially been successful in opening a door to developing a design for learning environments with ICT and also sharing programmes between the Nordic countries on the basis of 'give 4 and receive 16'.

There have been two major problems emerging from the Nordic Council of Ministers educational ICT initiatives. What has been done by the Nordic task force has been superb and unique, but the level of resources available for joint efforts has been so minimal that the impacts inevitably have been crucial for the educational ICT development in Nordic countries. This has been mainly due to lack of co-ordination and continuity on a national level in each of the countries.

\subsection{Iceland (Anna Kristiansdottir)}

Many activities with ICT in schools started earlier but were co-ordinated with a government plan for 1996-1999. Iceland is in a remarkable position in that $69 \%$ of all homes have a PC and $61 \%$ have access to Internet. The Icelandic Schoolnet started in 1991 through the private initiatives of a teacher, but was taken over by Iceland University of Education in 1996. The government is supporting integration of ICT into the whole community by providing special grants for the years 1999-2004.

\subsection{Norway (Sindre Røsvik)}

Norway has also integrated ICT in all plans for schools. It is considered important that all teachers and students become effective users of ICT, but it is also recognised that this has to happen with some economic constraints. Students should learn to use ICT to extend their learning both on subject matters and on methods of working. The main challenges for further development will be to support the teachers and activities in schools. It also calls for better administrative and political planning on all levels of education.

\subsection{Sweden (Kersti Hjertquist)}

Since 1983 the Swedish government has funded large national initiatives on ICT in schools. In 1995 a foundation was established to promote 
'Knowledge and Competence' on ICT in the whole school system. Through the years there has been a systematic effort to update the school system with teacher training, computer hardware and infrastructure. And yet today, the traditional pattern of 'one teacher using one book in one lesson in one class' still persists. The governmental initiative continues and now 60.000 teachers (1/3 of all teachers in Sweden) are participating in an in-service training programme which includes providing each teacher with a PC at home. The project deals with cross curriculum work using ICT in the classroom and is supported by facilitators coming to the schools. For basic computer skills, each school has to teach their own teachers. A major outcome of these initiatives is for all students to take responsibility for their own learning and to develop a passion for lifelong learning.

\subsection{Nordic Council of Ministers (Ulf Vasstrom)}

The collaboration between the Nordic countries has been supported by a formal organisation for more than 15 years. Since 1995 it has been the IDUN project: Nordic Co-operation on Information Technology and Didactics in Education which from 1999 shall be continued as IDUN II. The proposal for the IDUN II programme focuses on four key areas: innovative school environments, IT in teacher education, the education and training of adults and flexible learning. It is considered important that IT collaboration in education be an integral part of the general Nordic co-operation in education. With its focus on three sub-projects clearly linked to educational levels in the organisation of educational co-operation, the proposed structure does not mean that inter-sectorial collaboration and its potential for synergies will be lost. The three sub-projects will therefore have to be organised to ensure optimal interplay within the framework of the activities of IDUN II.

\subsection{Discussion}

Erik Dam, Denmark: With networks on all levels - local, national, Nordic, European and worldwide I am confronted with a problem where to put my ideas and take part in discussions. What is being done to connect such levels of information sharing? Ulf Vasstrom: It is most important that the national network is working and is connected to others' networks. Jiqing Wang, China: The Nordic collaboration is a nice project but would it continue without special funding? Ulf Vasstrom: I think so. Our budget is low - only 500.000 USD. Sindre Rosvik: Much is depending on national funding, which in fact is available. Jiqing Wang, China: How many courses are available? Ulf Vasstrom: We are sponsoring about 25 courses per year. 
Mike Aston: And the good thing is, that practitioners are participating - not politicians!

\section{FINNISH PROJECTS}

In their presentation Matti Sinko and Ella Kiesi provided a background and a framework for the presentation of a number of Finnish projects in ComNEd. The core problem of ICT in Finnish education as in any country is scaling up individual innovative practices. The projects presented should be understood as examples of such emerging good practices identified.

\subsection{Matilda-Telematic Literature}

Chair: Liisa Huovinen, FI

Presenter: Minttu Ollila, FI

Rapporteur: Lisbeth Appelberg, SE

Matilda is a Finnish online project for young book-lovers. The name of the group comes from Roald Dahl's book Matilda. A selected group of primary school children study literature in virtual study groups. They read two books a month and they discuss the books and exchange ideas by using the Matilda website (http://www.edu.espoo.fi/ matilda/) and email. Every school which takes part in Matilda has a teacher who works as a tutor. Teachers work with a home group of 8 students from 3-4 different schools. The Matilda website contains information about the reading programme and the assignments. Books are divided into eight categories according to their contents.

Everybody reads the'Book of the Month' chosen by the students. In addition to that, each student chooses one optional book from the same category. The students keep journals while reading the books. The idea is to reflect one's ideas and feelings in the journal and then share the impressions with the group by exchanging email. After reading a book the students send their assignment to the home group and tutor. Every student gets personal feedback from the tutor. The students are encouraged to comment on each others' ideas in order to have true interaction within the home group. In 1997-1998 there were 32 Matilda students from 6 different schools. This year there are more than 80 students from 11 schools and next year there will be even more students and schools taking part in the project.

In the presentation of the project Minttu Ollila pointed out some interesting outcomes of the project. These were that the students had really become interested in reading a broad variety of books and they also became ardent readers. In the beginning there were mainly girls taking part in the project but after a while the boys also became interested and some of them 
thought they had found a new world. Today the teachers have started other projects for 'booklovers'. They are Literature happenings and Literature theme days. For example, students dress up as characters from 'Alice in Wonderland' and go out in the forest and build up the story very much like the adventures happening in the story. Another example is 'Chamber of Horrors'. These are all planned by the students and many things are presented to the students in the lower grades. Minttu Ollila also mentioned that the face-to-face meetings for the virtual home groups 4-6 times per year had been of great importance.

Jaana Ikkala, Iiramaria Ojanen and Le The Cam Van, three students who had been in the project were in the panel to answer questions from the audience. All three of them thought that the project had been of great benefit and that the timetable concerning their work had been well organised. The teachers were very positive as well and the project is now growing faster than ever before. There are currently 20 schools involved from all over Finland.

\subsection{The teacher's changing role in Kaukajärvi Lower Secondary School}

Chair: Martti Piipari, FI

Presenter: Jari Ikola, FI

Rapporteur: Lisbeth Appelberg, SE

Kaukajärvi School has been engaged in a distance learning project from 1995 to 1998. This school has been working with distance learning, telecommunications applications and producing teaching material. Partners during the project were Digital Media Institute of Tampere University of Technology, Nokia Research Centre, Sonera, the Teacher Training School of the University of Tampere and hardware manufacturers. The aims of the project include increasing interaction, creating new learning environments, improving civic skills, developing multimedia material and utilising telecommunication applications.

The technical applications that have been used are video-conferencing via ATM, video-conferencing via ISDN, and video on demand.

The co-operation with the universities has been seen as very important as there was a need for scientific research. The advantages of networking included: it was easy to use, it increased international contacts, it increased contact with parents, and it increased co-operation with the surrounding community. It has also been a channel for advertising and has had an effect on the school's role and function. 


\subsubsection{Elementary course in Russian between Kaukajärvi School and the Teacher Training School of the University of Tampere}

This project involved a distance-learning elementary course in Russian between Kaukajärvi School and the Teacher Training School of the University of Tampere. The on-site class with the teacher was at the teacher training school. The remote class with six students was at Kaukajärvi School. As the students were not familiar with the equipment there was a technical assistant from Tampere University of Technology responsible for the computers and the video camera. The assistant also monitored and supported the group activities. The electronic learning material was mainly transmitted by using NetMeeting since email turned out to be too complicated. Russian was certainly not the easiest subject as a first trial in distance learning. To learn the Cyrillic alphabet and the pronunciation was not an easy task but the students did quite well considering the circumstances. This project helped to diminish prejudices against distance learning and encouraged teachers in other subjects to work in distance courses.

\subsubsection{Distance learning of mathematics}

One of the courses where they have used modern information technology to deliver distance learning at Kaukajärvi Lower Secondary School is mathematics. The project concentrated on the organisation of the course, the learning processes used for distance learning, the learning outcomes in Mathematics and ICT, the learner's motivation and the role of the teacher. Key aims of the project were to test the net and the suitability of different support programmes in studying mathematics as well as to revise and deepen the students' mathematical skills. The course content includes classroom studies and work at home. During six classroom lessons, the students were introduced to and worked with the programmes that they would use at home on their own computers. After this, there were 12 lessons delivered in distance learning mode. During the whole period there were two double lessons per week. In the beginning of the distance learning period the students were in contact with the teacher via Netmeeting. The teacher also sent exercises to the students via this mode. The students used the mathematical programme Ahjo to solve the problems. They were able to check their answers and if they had any problems they contacted the teacher via Netmeeting or the Ahjo-window. Using the Ahjo-window the teacher could see what the students had done and could give advice on how to proceed.

As there was not much material available the teacher had to prepare a lot of new material. The teacher also had to take in consideration the different 
level of the students and give them suitable exercises. There were some technical problems during the course but these were discussed and solved. The presenter told the audience that the students have been satisfied with the courses and it has been a challenge to the teacher as well. The students and the teachers have been solving problems together which illustrates a different way of teaching and learning. As a result of the project the school has changed the curriculum.

\subsection{FLE-tools: A World Wide Web-based application for collaborative learning}

Chair: Liisa Huovinen, FI

Presenter: Teemu Leinonen, FI

Rapporteur: Anna Kristiansdottir, IS

The Future Learning Environment (FLE) is an ambitious research and development project initiated by the Media Lab at the University of Art and Design in Helsinki (UADH). Research partners are from the Research Group of Applied Cognitive Science, Department of Psychology and also the Media Education Centre of the Department of Teacher Education, both at the University of Helsinki. The project has received financial support from the government as well as industry.

The aim of FLE is to explore the use of new media within learning, by generating a rich innovative learning environment and methods based on recent cognitive research and study of learning. The three research partners are focusing differently according to their particular research interest and educational activities. Some of the students who are trying out the FLE are working towards a Ph.D. or already University teachers, others are in their Masters studies. Having such a high quality of students the project is based on self-reliance, the students interact in a variety of ways with their teachers, tutors and each other.

Theoretically the FLE project refers to and makes use of the Inquiry Learning Process (Muukkonen, 1998) thereby supporting collaborative problem-solving, collaborative evaluation and development of metacognitive skills. The first Internet version, an inside prototype, was published in the beginning of 1999 including what is called FLE-tools which contain the following modules:

- Webtop, personal desktop in the web.

- Discussion for collaborate problem solving, knowledge construction and knowledge sharing.

- Jam Session for collaborative construction of artefacts. Creating and changing the model takes place here. 
- Library intended for publishing and browsing multimedia learning materials. Every participant can add links to the library.

- Administration which includes tools for administers users and groups.

FLE has a web-site. The URL is: http://mlab.uiah.fi/fle/ Further information about the public admission will be found on this site as the project runs into further stages.

\subsection{Creating and developing a centre for distance education}

Chair: Leena Vainio, FI

Presenters: Erkki Pitkanen and Paivio Peltokorpi, FI

Rapporteur: Anna Kristiansdottir, IS

The Centre for Distance Education is placed at the University of Jyväskylä and runs a service to teachers in the surrounding area and for students there in upper secondary schools and primary schools. There is a co-operation with the Finnish National Board of Education which is the primary financial supporter of the project. This project is running in accordance with the programme for an information society developed by the Ministry of Education and the National Board of Education.

It can be said that this project takes pride in using what is already available and possible and to allow teachers and students around the University of Jyväskylä to benefit from the equipment, wealth of resource found on the University computer and human expertise at the university. By this project the following was thus considered of great importance:

- Multivariate learning environment, accessible even by means of a modem and a basic PC.

- Distance learning should be possible without video conferencing.

- An easy way should be offered, versatile resources and computer technology expertise of the centre to remote users.

- It should be inexpensive to become a user.

- No special skills in computer technology should be needed, everyday applications offered for use.

- The centre should be a pedagogically functioning entity.

Courses available from the centre include philosophy, French, history and mathematics. Furthermore one student who moved to USA could through the service of the centre continue studying with his Finnish classmates. The centre has made it possible to open up for new optional subjects for primary school students in the areas, made interaction with distant classmates virtually real and helped students to increase social skills, initiativeness, responsibility and communication. The students have been enthusiastic and made many new contacts. There have been some technical 
drawbacks with weak sound quality and time consuming explanations and instruction. This is being looked into to develop the work further. The centre has a website whose URL is: http://www.norssi.jyu.fi

\subsection{NetD@ys in Finland}

Chair:Martti Pipari, FI

Presenter: Riitta Karvinen, FI

Rapporteur: Lisbeth Appelberg, SE

NetD@ys started in Silicon Valley in 1996 as a project to have schools working on the Internet in a friendly learning network. NetD@ys Europe 1998 was presumed to be the largest educational technology event in Europe. Approximately 35000 schools participated in the project and organised various activities. According to the analysis approximately $77 \%$ of the projects focused on facilitating awareness of the pedagogical possibilities offered by ICT and the Internet. Many of the projects focused on facilitating the acquisition of subject-matter knowledge. Others represented initial attempts at starting to use ICT in some specific educational environments. Students who took part in the project found the use of ICT very motivating. It is now important not only to focus on improving students' and teachers' technical skills but also to guide them to use ICT as a tool for teaching and learning.

NetD@ys 99 will be held from 13-21 November 1999. The opening events will be arranged in Helsinki on the 12 November and it will be possible to follow on the Web, radio and TV. There will be a great number of projects from many countries. These include Mediterranean cooking, The circus is in town!, Europe goes opera, Internet del Arte, This is no normal museum, Learning science is fun, Space fun, and Where was my town three centuries ago? More information on these events can be obtained from the NetD@ys Europe 99 site: www.netdays $99.0 r g$

\subsection{Flexible learning over the high speed Internet Web University}

Chair: Matti Sinko, FI

Presenter: Riita Rinta-Filppula, FI

Rapporteur: Anna Kristiansdottir, IS

Web University (WU) started in 1996 as an international co-operative pilot project between CERN (European Laboratory Particle Physics) and Finnish universities. Since 1997 a collaboration has taken place with the Finnish Distance Learning in Multimedia Network project (ETÄKAMU). The project has on its agenda to trial out high technology for work of 
researchers, teaching and learning in an international networked environment. It has since 1996 extended its transmissions to Holland, Italy and Slovak.

WU has developed and explored working, teaching and learning methods in an international network environment. Students have been able to select spesialised seminars agreed by the local professors to be a part of their studies and researchers have had opportunity for distance work and collaboration as well as tailored in-service courses. Transmissions are realtime and selected seminars and lectures are available as videos on demand. These are provided by the Wrtp project developed at the IT/CS Group.

Among the pedagogically important conclusions are the importance of preparing sessions well in advance; distributing presentation material before sessions via WWW, giving learners time to adapt go the new learning situation, having credits as a motivation for undergraduate students and the latest research results for the post graduates. Among areas to give future attention are content production and development and adaptation of group work methods to new high speed network tools. Further information: Riitta.Rinta-Filppula@cern.ch 